DOI: 10.35784/IAPGOS.233

\title{
THE ANALYSIS OF APPROACHES TO MEASUREMENT UNCERTAINTY EVALUATION FOR CALIBRATION
}

\author{
Sarsenbek S. Zhussupbekov, Svetlana G. Khan, Lida K. Ibrayeva \\ Almaty University of Power Engineering and Telecommunications, Almaty, Kazakhstan
}

Abstract. A comparative analysis of the measurement uncertainty estimation result is carried out. The results are obtained by GUM method described in the Guide to the expression of uncertainty in measurement, as well as by Monte-Carlo method recommended in Supplement 1 to the Guide. Examples of calculations of uncertainty of relative error for electromagnetic flow meters calibration by two methods are given. The features of application, advantages and disadvantages of these methods are described.

Keywords: measurement uncertainty, GUM and Monte Carlo uncertainty estimation methods, calibration of an electromagnetic flowmeter

\section{ANALIZA PRZYPADKÓW W OCENIE NIEPEWNOŚCI POMIARU NA POTRZEBY KALIBRACJI}

\begin{abstract}
Streszczenie. W pracy omówiono analize porównawcza wyniku oszacowania niepewności pomiaru. Wyniki uzyskano metoda GUM, opisana w przewodniku do wyrażania niepewności pomiaru, a także metoda Monte-Carlo zalecana w Suplemencie 1 do tego przewodnika. Podano przykłady obliczén niepewności błędu względnego dla kalibracji przeplywomierzy elektromagnetycznych za pomoca dwóch metod. W artykule opisano cechy zastosowaia, $w$ tym: zalety oraz wady tych metod.
\end{abstract}

Slowa kluczowe: niepewność pomiaru, metody szacowania niepewności GUM i Monte Carlo, kalibracja przepływomierza elektromagnetycznego

\section{Introduction}

At present, the quantitative expression of measurement quality implies the measurement uncertainty. The term "measurement uncertainty" is in the international metrology vocabulary VIM [6], and the basic principles of the concept of uncertainty are set out in document [5]. The ability to assess the measurement uncertainty is one of the requirements confirming the competence of calibration laboratories of any level and presented in international standards [4]. There are several approaches to the estimation of measurement uncertainty:

1. The fundamental approach GUM [5] is based on the mandatory compilation of a mathematical model (usually linear or linearized) of the measurement process and the calculation of the standard uncertainty of the measured value on the basis of the law of uncertainty transformation. Due to the wide spread and methodological convenience of application, the approach according to GUM is often called classical;

2. The first Supplement to GUM (GUM-S1) [3] describes a method of uncertainty estimation based on numerical Monte Carlo simulation. In this Supplement, GUM approach is developed and the scope of the methodology is extended by using the law of transformation of distributions for both linear and nonlinear measurement models. For linear and linearized measurement functions and input values subject to normal distribution, this approach is consistent with GUM approach. However, if the conditions of GUM approach application are not fulfilled, the use of GUM-S1 allows to obtain more reliable and reasonable estimates of uncertainty than the classical method (this fact is described and confirmed by the example in [1]). Therefore, the approach according to GUMS1 can be used both for calculation of measurement uncertainty and for validation of the results obtained in accordance with GUM. At the same time, data processing is performed by Monte Carlo method (MMK) with the help of special software.

To control the technical condition of the flowmeters it is necessary to carry out their periodic calibration. The existing calibration procedure requires the dismantling of the flowmeters from work positions. All this significantly affects the workflow and leads to an increase in production costs.
The purpose of the work is to perform uncertainty calculations of the relative error in the calibration of electromagnetic flowmeters by two methods: GUM and Monte-Carlo using NI LabView graphical programming software.

\section{Problem statement}

"The Guide to the Expression of Uncertainty in Measurement" (GUM-1993) considers two approaches to quantifying measurement uncertainty evaluation: GUM method and Monte Carlo simulation method. Both of these methods are applied by the authors in the task of evaluation the uncertainty of measuring a Coriolis flowmeter applied as an etalon (standard) [7].

In GUM method the main stages in evaluation of uncertainty include the formulation of the measurement task and the calculations. At the stage of formulation of the measurement task the following tasks are conducted: determination of the output (measured) value; identification of input values on which the output value depends; drawing up a measurement model. The calculation stage consists of calculating the mean of the output value, this mean is taken as the value of the estimated output value; standard deviation of the output value taken as standard uncertainty; coverage interval containing the output value with a given probability of coverage.

The algorithm for evaluation the uncertainty using this method is given in [5].

The idea of Monte Carlo method is as follows: each time the measurement function is calculated, the generated random values of input variables are substituted into it, varying around their nominal value within the uncertainty interval in accordance with the distribution law.

To apply the Monte Carlo method, it is necessary to select the number $m$ of model estimation that you need to produce, and the level of confidence $p$. It is best to choose the value of $m$ a large enough compared to $1 /(1-p)$, (for example, exceeding it $10^{6}$ times). The algorithm of Monte Carlo method is given in [4].

\section{The research and calculations}

In this article the authors explore the application of these methods to evaluate the measurement uncertainty of two working electromagnetic flowmeters (EMF\#1 and EMF\#2). 
The evaluation of the measurement uncertainty by GUM method is conducted on the basis of the standard of the Republic of Kazakhstan "Method of calibration of electromagnetic flowmeters" [2]. This standard regulates the evaluation of the uncertainty of the relative error of an EMF and offers the measurement model of the following type:

$$
\delta=\frac{Q_{r}-Q_{p}}{Q_{p}} \times 100,
$$

where $Q_{\mathrm{r}}$ is the result of flow measurement by an EMF; $Q_{p}$ is the result of flow measurement with a calibration equipment (CE) (a standard Coriolis flowmeter in our work).

The calculation of the measurement uncertainty evaluations includes the evaluations of the uncertainty for type $A$ and type $B$.

The calculation of type $A$ uncertainty includes the statistical processing of the measurement results of the EMF and the CE: the calculation of the mean, variance and standard deviation.

The standard uncertainty of the EMF relative error on type $A$ is found by the formula:

$$
u_{A}(\delta)=\frac{\sigma(\delta)}{\sqrt{3}}, \quad \sigma(\delta)=\frac{\sigma(\Delta)}{\sqrt{n} \cdot Q_{p}} ;
$$

where $\sigma(\Delta)$ is the standard deviation of the EMF absolute error; $n$ is the number of measurements.

The type $B$ uncertainty calculation includes:

1) The uncertainty of the readings of the electromagnetic flowmeter $Q_{r}$, due to the discreteness of the readings of the EMF $d_{r}$ assuming the rectangular probability distribution:

$$
u_{B 1}\left(Q_{r}\right)=\frac{d_{r}}{2 \sqrt{3}},
$$

2) The uncertainty of the $\mathrm{CE}$ readings is indicated in the document on it. In case of specifying in the document on $\mathrm{CE}$ only its errors $\Delta p$, assuming a rectangular probability distribution:

$$
u_{B 2}\left(Q_{p}\right)=\frac{\Delta p}{\sqrt{3}},
$$

where $\Delta p$ is the $\mathrm{CE}$ error;

3) the uncertainty of CE indications due to the discreteness of its testimony, in the assumption of a rectangular probability distribution:

$$
u_{B 3}\left(Q_{p}\right)=\frac{d_{p}}{2 \sqrt{3}} .
$$

The total uncertainty of type $B$ of EMF relative error is calculated by the formula:

$$
u_{B}\left(\delta_{Q}\right)=\sqrt{C_{Q_{r}}^{2} u_{B 1}^{2}\left(Q_{r}\right)+C_{Q_{p}}^{2}\left(u_{B 2}^{2}\left(Q_{P}\right)+u_{B 3}^{2}\left(Q_{P}\right)\right)},
$$

where $C_{Q r}$ is the sensitivity coefficient of the EMF:

$$
C_{Q r}=\frac{100 \%}{Q p} ;
$$

where $C_{Q p}$ is the sensitivity coefficient of the $\mathrm{CE}$ :

$$
C_{Q p}=-\frac{Q_{r} 100 \%}{Q_{p}^{2}} .
$$

To calculate the total standard uncertainty of the EMF relative error, the formula is applied:

$$
u_{c}\left(\delta_{Q}\right)=\sqrt{u_{a}^{2}\left(\delta_{Q}\right)+u_{B \Sigma}\left(\delta_{Q}\right)} .
$$

The calculation of the expanded uncertainty of the EMF relative error is fulfilled applying the formula:

$$
U_{c}\left(\delta_{Q}\right)=k \cdot u_{c}\left(\delta_{Q}\right) \cdot
$$

Based on the above formulas the algorithms and programs have been developed for calculating the relative error of the EMF by two methods. The programs are implemented in the NI LabView graphical software. The use of NI LabView software is due to the fact that the measurement uncertainty calculation programs described below will be used in the Automated Workplace (AWP) of the Metrologist which uses the equipment of NI Company.

GUM method calculation. The initial data are the readings of the EMF and the Coriolis flowmeter (as CE) received on the laboratory equipment of the GIMC. The experiment means the measurement of the flow value of $0.95 Q_{\max }, \mathrm{dm}^{3} / \mathrm{h}\left(Q_{\max }\right.$ is the maximum value of the measurement range of the calibrated EMF) by the calibrated flowmeter $-Q_{\mathrm{r}}$ and by the Coriolis flowmeter $-Q_{p}$; the number of experiments is 11 .

To determine the type $B$ uncertainty according to the formulas (3-5), the values of the relative error and discreteness of the EMF readings and the $\mathrm{CE}$ are specified.

As a result of the calculation a measurement uncertainty budget has been compiled, into which the uncertainty components of the EMF relative error calculated by the above formulas (3-10) are entered. The program interface with the results of calculating the budget uncertainty of the EMF relative error is shown in Fig. 1.

Monte-Carlo method calculation. The next stage of the research work was to apply Monte-Carlo method to evaluation the uncertainty of the EMF relative error. The modelling of the process of evaluation the uncertainty of the EMF relative error was performed as follows:

1) two arrays of random numbers, obeying the uniform distribution laws, of volume $m=10^{6}$ for input variables are generated:

- $Q_{\mathrm{r}}$ - the flow measurement results by the electromagnetic flowmeter;

- $Q_{p}$ - the flow measurement results by the calibration equipment (Coriolis flowmeter);

2) an array of output value - the EMF relative error $\delta$ was generated;

3) estimates of the parameters of the obtained distribution are calculated:

- mean value: $M(\delta)=\frac{\sum_{1}^{11} \delta_{i}}{11} ; \widehat{M}$ where $\delta_{i}$ is calculated by the (1);

- total standard uncertainty: $u_{c}(\delta)=\sqrt{\frac{\sum_{1}^{11}\left(\delta_{i}-M(\delta)\right)^{2}}{10}}$;

- expanded uncertainty: $U(\delta)=\frac{1}{2}\left[\delta_{975000}-\delta_{25000}\right]$;

- coverage coefficient: $k=U(\delta) / u_{c}(\delta)$;

4) obtained measurement result: $\delta \pm U(\delta) \%$; $p=0.95$.

The program interface with the calculation results of the EMF relative error uncertainty by Monte-Carlo method is shown in Fig. 2.

The analysis of the received results. Ten experiments were carried out for one nominal value of the measured flow for calibration of two flow meters. The processing of the obtained experimental data was carried out by both methods - GUM and Monte-Carlo. The uncertainty values of the EMFs relative error $U(\delta)$ are given in Fig. 3, Fig. 5.

According to these data, the graphs of the dependence of the relative error uncertainty on the number of the experiment ( $x$-axis is the number of the experiment) obtained by both methods were plotted (Fig. 4, Fig. 6). 


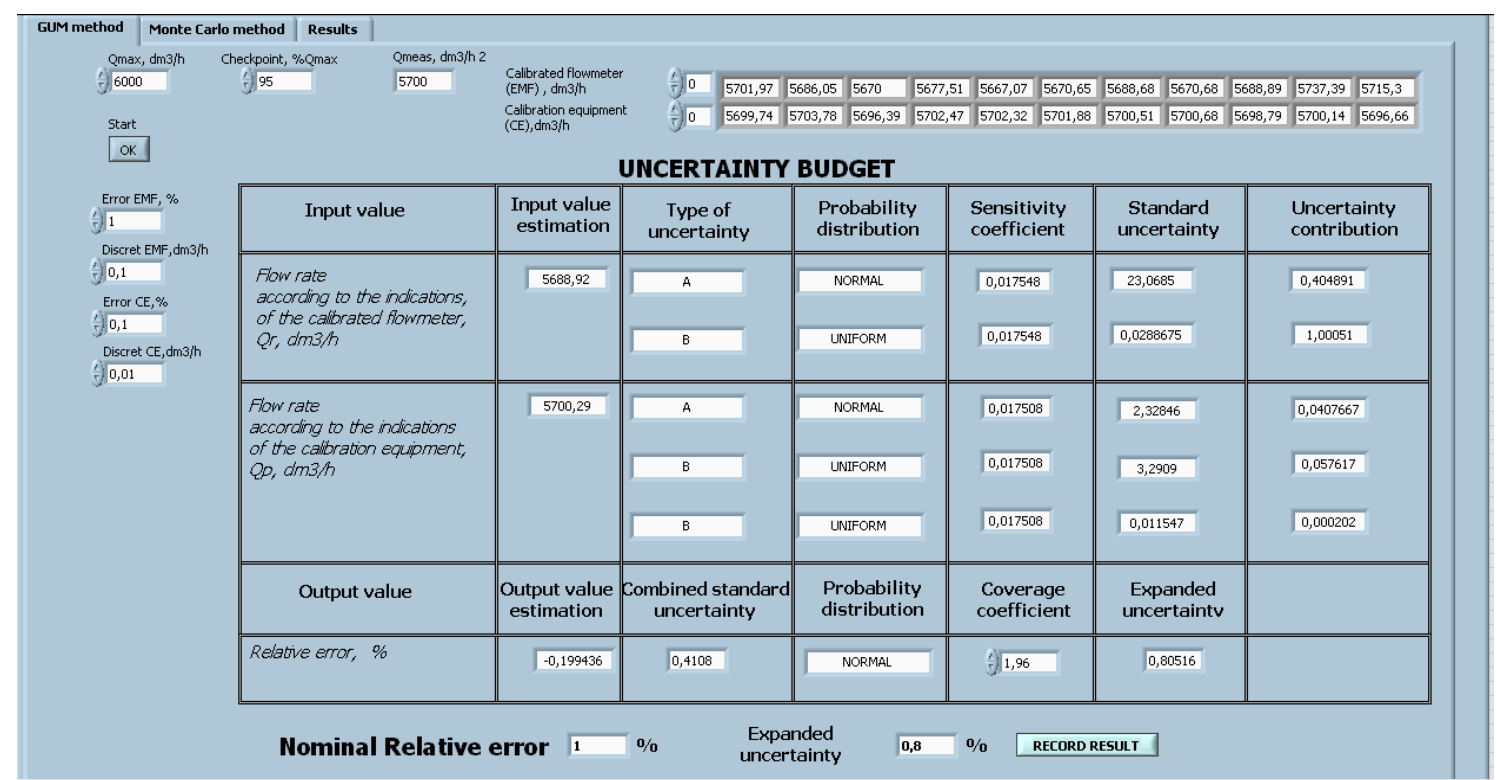

Fig. 1. The uncertainty budget of the EMF relative error

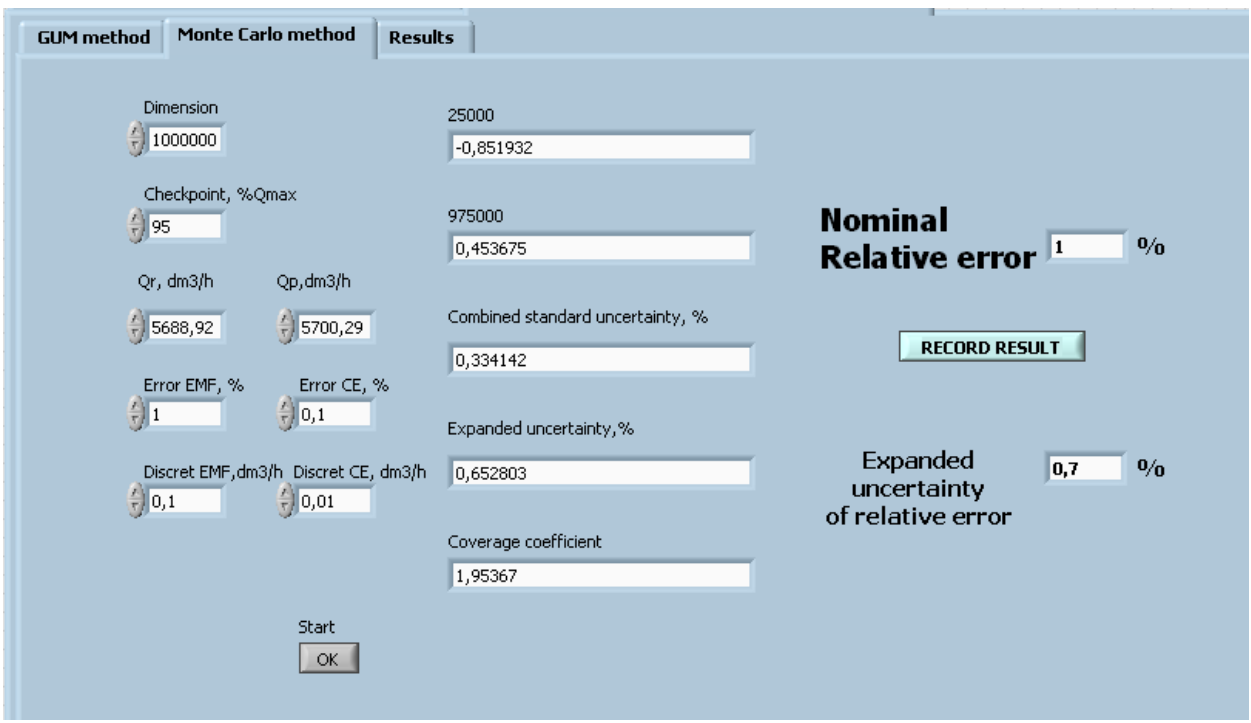

Fig. 2. The calculation results of the EMF relative error uncertainty by Monte-Carlo method

\begin{tabular}{|c|c|c|c|c|c|c|c|}
\hline & \multirow[b]{2}{*}{ ERROR-GUM } & \multirow[b]{3}{*}{$\frac{1}{5} 0$} & \multirow{2}{*}{\multicolumn{2}{|c|}{ UNCERT ERR-GUM }} & \multicolumn{3}{|c|}{ RELATIVE ERROR UNCERTAINTY } \\
\hline & & & & & ERROR-MC & & UNCERT ERR-MC \\
\hline 0 & a) $-0,0317$ & & 0,313 & $\frac{1}{5} 0$ & A $-0,0317$ & (5) 0 & 0,4557 \\
\hline & $-0,0219$ & & 0,378 & & a) $-0,0219$ & & 0,4553 \\
\hline & $-0,0287$ & & (1) 0,419 & & 1.) $-0,0287$ & & 0,4548 \\
\hline & $-0,0211$ & & 0,391 & & A $-0,0211$ & & $=0,4542$ \\
\hline & 국 $-0,0279$ & & 0,351 & & $-0,0279$ & & 0,4553 \\
\hline & 슨 $-0,0324$ & & 0,416 & & $\begin{array}{ll}1 & -0,0324\end{array}$ & & 0,4546 \\
\hline & $-0,0242$ & & 0,338 & & ㄱ. $-0,0242$ & & 0,4555 \\
\hline & $-0,0244$ & & t) 0,419 & & t) $-0,0244$ & & 0,4548 \\
\hline & $-0,0267$ & & 는,271 & & 1) $-0,0267$ & & 0,4548 \\
\hline & A) $-0,0283$ & & 0,331 & & 1) $-0,0283$ & & a) 0,4548 \\
\hline & (1) $-0,0288$ & & t) 0,336 & & (1) $-0,0288$ & & (1) 0,4548 \\
\hline
\end{tabular}

Fig. 3. Experimental data obtained by GUM and Monte-Carlo methods for EMF \#1

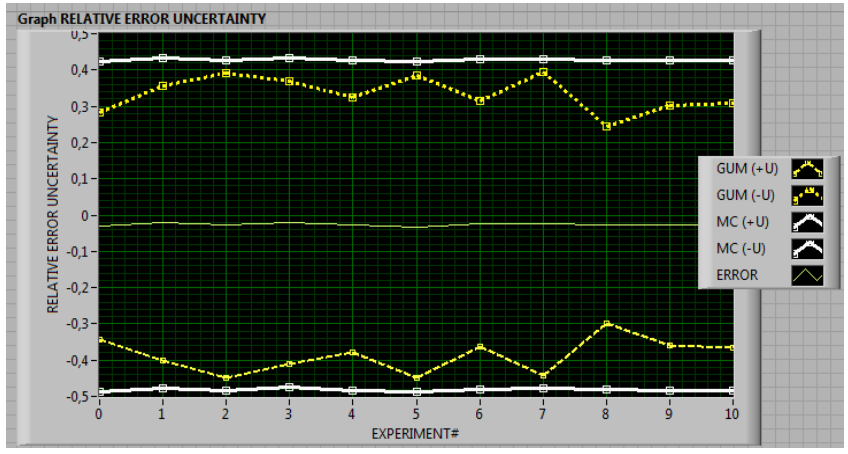

Fig. 4. The graphs of the dependence of the relative error uncertainty on the number of the experiment for EMF \#1 


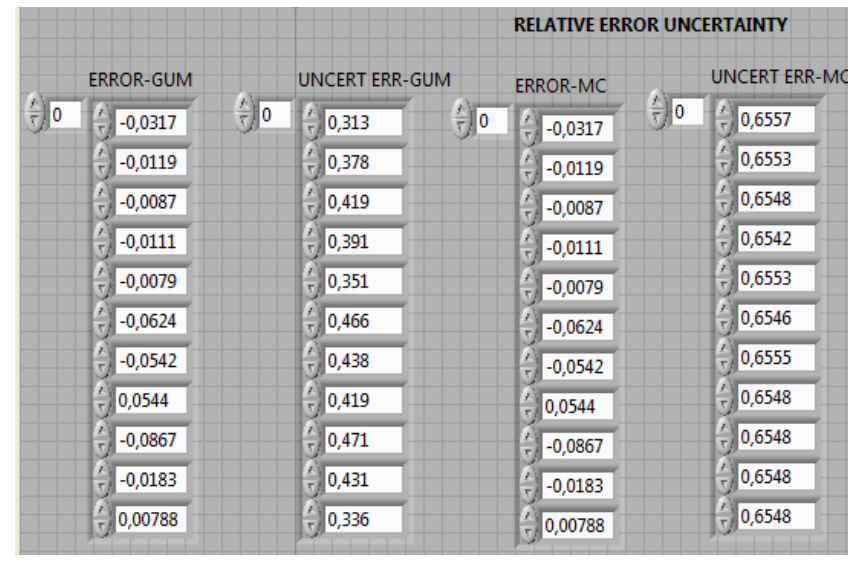

Fig. 5. Experimental data obtained by GUM and Monte-Carlo methods for EMF \#2

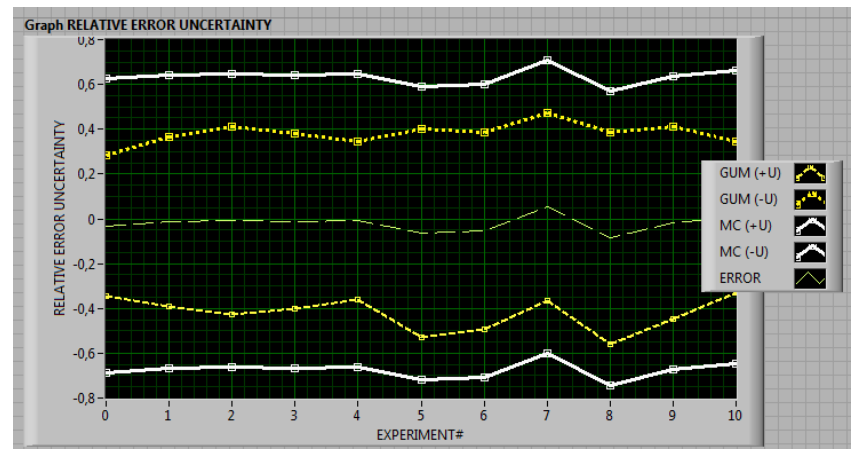

Fig. 6. The graphs of the dependence of the relative error uncertainty on the number of the experiment EMF \#2

\section{Analysis}

The graphs received by Monte Carlo method (solid lines) show a constant value of the uncertainty scatter of the relative error within $\pm 0,42 \%$ for EMF \#1 (Fig. 3, 4). The graphs received by Monte Carlo method (solid lines) show a variable value of the uncertainty scatter of the relative error within $\pm 0,65 \%$ for EMF $\# 2$ (Fig. 5, 6). This is due to the fact that various laws of generation (normal and uniform) of flow meter errors were used for the research by MC method. With a uniform distribution law (for $E M F \# 1$ ), there is practically no scatter of relative error on the graph. For the normal distribution law (for $E M F \# 2$ ), the graph shows that the coverage interval of the relative error is variable. However, for both EMRs, the relative error coverage intervals are within the permissible relative errors of EMFs which equal $\pm 0,5 \%$ (for EMF \#1) and $\pm 1 \%$ (for EMF \#2).

The graphs received by GUM method (dotted lines) (Fig. 4, 6) show a variable value of scatter of uncertainty of the relative error for both EMFs, because they are plotted on the experimental data. In both cases, the relative error less than the results of calculation by Monte Carlo method, and less than the limit of permissible relative error of EMFs.

\section{Conclusion}

Research and obtained results let make the conclusions:

1) There are minor differences in the results of calculations by both methods.

2) Monte-Carlo uncertainty values exceed GUM values but do not exceed the permissible relative error. That is GUM method provides high accuracy in evaluation of the measurement uncertainty.

3) Monte Carlo calculation takes more time (due to sorting and processing of large arrays). But it can be performed by less qualified personnel (no deep knowledge of mathematics is required).

4) Monte Carlo method can be considered as a practical alternative to GUM uncertainty evaluation method.

\section{References}

[1] Efremova N.Yu., Chunovkina A.G.: Development of the concept of "measurement uncertainty" and revision of the "Guide to the expression of measurement uncertainty". Part 1. Reasons and theoretical-probability basis of the revision. Measurement techniques 4/2016, 9-14.

[2] Electromagnetic flowmeters. Method of calibration: Committee for Technical Regulation and Metrology of the Republic of Kazakhstan. SD RK 2.328-2015. Astana 2015.

[3] Evaluation of measurement data - Supplement 1 to the "Guide to the expression of uncertainty in measurement". Propagation of distributions using a Monte Carlo method. JCGM 101:2008, 2008

[4] General requirements for the competence of testing and calibration laboratories. ISO/IEC 17025:2017, 2017.

[5] Guide to the Expression of Uncertainty in Measurement: First Edition. ISO(GUM:1993), Switzerland 1993.

[6] International Vocabulary of Metrology - Basic and General Concepts and Associated Terms (VIM), JCGM 200:2012, 2012.

[7] Khan S.G., Tashibayeva A.E., Bukayeva G.: Development of program for estimating of Corolis flowmeters' measurement uncertainty. Vestnik AUPET $1(40) / 2018,34-39$.

Ph.D. Sarsenbek Zhussupbeko

e-mail: zhussupbekovs@mail.ru

Ph.D., Professor of Almaty University of Power Engineering and Telecommunications, Almaty, Kazakhstan.

Born in 25.11.1956, South Kazakhstan region.

Graduated from Kazakh Polytechnic Institute in 1982 More than 70 scientific articles and theses in local and international scientific journals.

ORCID ID: 0000-0003-3220-713X

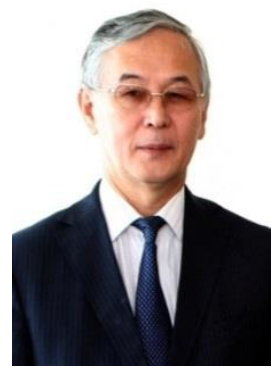

\section{Ph.D. Svetlana Khan}

e-mail: khan.sv2011@ gmail.com

Ph.D., Professor of Almaty University of Power Engineering and Telecommunications, Almaty, Kazakhstan.

Born in 18.07.1955, Almaty region.

Graduated from Leningrad Electrotechnical Institute,

Department "Electronic Medical Equipment" in 1978 More than 200 scientific articles and theses in local and international scientific journals.

ORCID ID: 0000-0002-7918-6690

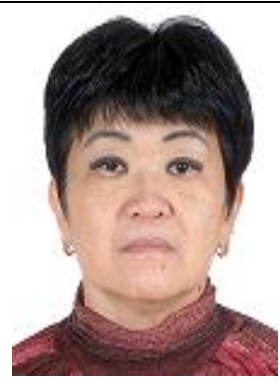

Ph.D. Lida Ibrayeva

e-mail: ibrayeva_lk@mail.ru

Ph.D., Professor of Almaty University of Power Engineering and Telecommunications, Almaty, Kazakhstan.

Born in 21.01.1950, Aktobe region.

Graduated from Kazakh State University in 1973.

More than 118 scientific articles and theses in local and international scientific journals.

ORCID ID: 0000-0002-8342-6685



otrzymano/received: 30.05 .2019

przyjęto do druku/accepted: 15.06 .2019 